\title{
Ambient Air Pollution and Pulmonary Tuberculosis in Malaysia
}

\author{
Mohd Hatta Abdul Mutalip1", Tee Guat Hiong1, Stefanie Ebelt Sarnat2, Mohd Hazrin Hashim1, \\ Noor Aliza Lodz' ${ }^{1}$ Sayan Pan',3, Mohd Shahrul Mohd Nadzir ${ }^{4}$, Asmah Razali ${ }^{5}$ \\ ${ }^{1}$ Center for Communicable Disease Research, Institute for Public Health, Ministry of Health Malaysia, Kuala Lumpur, Malaysia \\ ${ }^{2}$ Department of Environmental Health, Emory University, Rollins School of Public Health, Atlanta, GA, USA \\ ${ }^{3}$ Food Safety Division, Perlis State Health Department, Kangar, Malaysia \\ ${ }^{4}$ Institute of Climate Change, Universiti Kebangsaan Malaysia, Bangi, Malaysia \\ ${ }^{5}$ TB Sector, Disease Control Division, Ministry of Health Malaysia, Federal Government Administration Centre, Putrajaya, \\ Malaysia \\ Email: `hatta.mutalip@gmail.com
}

How to cite this paper: Mutalip, M.H.A., Hiong, T.G., Sarnat, S.E., Hashim, M.H., Lodz, N.A., Pan, S., Nadzir, M.S.M. and Razali, A. (2018) Ambient Air Pollution and Pulmonary Tuberculosis in Malaysia. Health, 10, 1634-1649.

https://doi.org/10.4236/health.2018.1012123

Received: October 24, 2018

Accepted: November 30, 2018

Published: December 3, 2018

Copyright $\odot 2018$ by authors and Scientific Research Publishing Inc. This work is licensed under the Creative Commons Attribution International License (CC BY 4.0).

http://creativecommons.org/licenses/by/4.0/

\begin{abstract}
Introduction: The possible impact of ambient air pollution exposure on the development of active tuberculosis (TB) remains obscure. This study investigated the potential role of ambient air pollution in activating pulmonary $\mathrm{TB}$ (PTB) compared to extrapulmonary TB (EPTB). Materials and Methods: Data on TB cases were obtained from national surveillance data in Malaysia during 2013 and air pollution data were obtained from 52 air-monitoring stations around the country for the 3-year period of 2011-2013. Analyses were performed to estimate the odds of PTB vs. EPTB with changes in the 3-year (2011-2013) average Air Pollutant Index (API) and specific ambient air pollutants. Results: Results showed that the 95th-percentile of API levels during 2011-2013 was moderate and it was not associated with PTB. However, the odds of active PTB compared to EPTB was significantly elevated with the 95th-percentile levels for particulate matter with an aerodynamic diameter of $10 \mu \mathrm{m}$ or less $(\mathrm{aOR}=1.006,95 \% \mathrm{CI}: 1.002,1.011)$, $\mathrm{p}$-value $<0.01$, and sulfur dioxide $(\mathrm{aOR}=1.012,95 \% \mathrm{CI}: 1.006,1.019)$, p-value $<0.01$. Conclusions: These results provide suggestive evidence of the effects of ambient air pollution on development of active pulmonary $\mathrm{TB}$ compared to extrapulmonary TB. Additional research on the impacts of ambient air pollution on TB is warranted.
\end{abstract}

\section{Keywords}

Ambient Air Pollution, Air Pollutant Index, Pulmonary TB, Malaysia 


\section{Introduction}

Tuberculosis (TB) remains a major global health problem, significantly affecting millions of people each year, mostly from low and middle-income countries (LMICs) [1]. Among all the communicable diseases, TB ranks as one of the top 10 causes of death worldwide [2]. TB is an airborne infectious disease caused by the bacillus Mycobacterium tuberculosis, which spreads from a person with active TB infection to others through fine respiratory droplet nuclei. A person infected with M. tuberculosis does not necessarily have TB symptoms, as the host immune system may protect against or suppress the bacteria, resulting in an inactive and non-infectious latent TB Infection (LTBI) [3]. According to the World Health Organization (WHO), about one-third of the world's population has LTBI with $10 \%$ lifetime risk of developing active TB [4]. The risk of acquiring an active TB infection is higher among those with compromised immune systems, such as malnutrition, people living with human immunodeficiency virus (HIV) or diabetes or people who use tobacco [4]. Typically, most people with active $\mathrm{TB}$ acquire pulmonary $\mathrm{TB}$ ( $\mathrm{PTB})$, which affects the lungs and respiratory tract and is characterized by chronic cough, chest pain, fatigue, weight loss, fever and night sweats. Extrapulmonary TB (EPTB) also exists, in which the disease spreads beyond the lungs and affects other parts of the body, such as the brain, intestines, kidneys or spine; immunodeficient individuals and children are more susceptible than others to EPTB.

Recently, WHO reported there were 1.3 million deaths attributed to TB, of which 374,000 were among HIV-infected people [1]. It also estimated that there were 10.4 million new TB cases, including $10 \%$ new TB cases co-infected with HIV [1]. The TB was found predominantly in adults, with an estimated 6.7 million cases in men, 3.7 million cases in women and 1.4 million cases in children; for an overall ratio of 9:1 for adults to children [1]. There have been numerous efforts to curtail TB incidence, such as providing access to effective diagnostic and treatment options, but TB remains a threat to health. Despite substantial progress in global TB control, TB is still a burden in WHO South-East Asia region, WHO African region and the WHO Western Pacific region [1]. In addition, global multidrug resistance increases the challenge of TB treatment and certain bacterial strains are impervious to common first line TB treatment [3]. The burden of multidrug resistant TB (MDR-TB) and extensively drug resistant $\mathrm{TB}$ (XDR-TB) will impede eradication of TB as more people show resistance to the first line treatment.

Numerous studies have examined risk factors for TB disease. Social determinants are major contributors to the increased of incidence of active TB in poor and limited resource settings [5] [6]. However, the trend of TB risk has shifted as rises in comorbidities such as diabetes, alcohol drinking and physical inactivity have substantially contributed to higher risks of TB infection even in developed countries [7]. Studies also have shown that indoor air pollution from fossil gas cooking, smoking and exposure to secondhand smoking impair pulmonary function, and are also strongly associated with increased of TB incidence [8]. 
There are limited studies have assessed the potential impact of ambient air pollutant exposure on TB. Exposure to high concentrations of air pollution could affect airways and alter host defense where air pollution could interfere with mucociliary clearance and macrophage function, thus impairing immune response to respiratory tract infections [9]. Immune impairment in the lungs by air pollutants might accelerate proliferation of $M$. tuberculosis, resulting in active TB. Without immune protection, the bacterium may further disseminate to lymph nodes within the lung and spread to remote sites in human body [10].

With rapid urbanization and industrialization, more people are being exposed to urban ambient air pollution in their daily lives [11]. In 2014, WHO reported that $92 \%$ of the world population lived in places with air quality levels exceeding the WHO air quality standards [12]. WHO also reported there were three million premature deaths worldwide attributable to ambient air pollution, with $88 \%$ of those deaths occurring in low and middle-income countries, especially in the Western Pacific and South East Asia regions [12]. Long-term exposure to ambient air pollution has a significant impact on health outcomes, and prolonged exposure to air pollution could increase the risk of asthma, other respiratory illness and cardiovascular diseases [13].

The incidence rate of TB in Malaysia has been rising over the years [14] [15]. In 2016, Malaysia had a total of 25,739 new cases, an annual TB incidence rate of 92 cases per 100,000 population, and an attributed mortality rate of 5.1 cases per 100,000 population [1]. Notably, the increasing trend of TB cases was observed in populous states, urban areas and industrialized cities [6] [14]. Previous studies in Malaysia have reported multiple factors associated with the risk in TB incidence [6] [15]. One major contributory factor has been the influx of immigrants to Malaysia [6] [14]. Urban populations, especially those in crowded dwellings and slum areas, have been identified among the most susceptible population to TB infection [6].

Ambient air pollution may be a contributing factor for TB disease in Malaysia. However, more evidence is needed to identify the potential role of ambient air pollution in driving TB disease activation. There are very limited studies investigating the health effects associated with exposure to ambient air pollution in Malaysia [16]. To help identify potential role of ambient air pollution on incidence of PTB in Malaysia, we investigated ambient air pollution exposures that could specifically activate the development of pulmonary compared to extrapulmonary TB disease. As progression from LTBI to TB disease takes one to two years [17], we used an exposure window of ambient air pollution for approximately three years to identify these exposures that potentially exacerbate PTB.

\section{Materials and Methods}

\subsection{Study Design}

This study was an ecological cross-sectional study design utilizing retrospective cohort data on confirmed TB patients in Malaysia in the year 2013. Data were 
extracted from the Tuberculosis Information System (TBIS); a national surveillance record of TB patients compiled by the Ministry of Health (MOH) Malaysia. TB is a notifiable disease under the Malaysian law, hence, it is mandatory for all healthcare providers in Malaysia to report TB cases via TBIS as part of nationwide TB surveillance [18]. This study obtained the Medical Research and Ethics Committee approval from the Ministry of Health Malaysia. Patients' identification was kept anonymous for confidentiality.

\subsection{TB Cases and Covariates}

All confirmed TB cases in Malaysia for the year 2013 were included. TB diagnoses were made based on clinical, radiological and bacteriological evidences using definitions from the standard Clinical Practice Guideline of Tuberculosis, Malaysia [18]. We excluded all immuno-compromised TB patients; those diagnosed with XDR-TB, MDR-TB and TB-HIV since these patients might respond to air pollution differently than patients with regular TB. The dependent outcome variable was binary where $\mathrm{TB}$ was classified pulmonary $\mathrm{TB}$ (PTB) or extrapulmonary TB (EPTB) based on anatomical site of infection.

The surveillance data include information on Patients' socio-demographic characteristics included in this study were state of residence, gender, age, citizenship and ethnicity. Socio-economic status (SES) was measured based on education and income levels. TB host-related factors included status of BCG scar, history of TB infection and crowding categorized as less than 5,5 to 10 people and more than 10 people in a dwelling. Tobacco use was included as a proxy for indoor air pollution exposure and diabetes status was used as a proxy for cardiovascular disease.

\subsection{Air Pollution Exposure Estimation}

Data on air pollutants were obtained from the Department of Environment, Ministry of Natural Resources, Malaysia. The Air Pollutant Index (API) and other five major air pollutants with potential adverse effects on human health: nitrogen dioxide $\left(\mathrm{NO}_{2}\right)$, ozone $\left(\mathrm{O}_{3}\right)$, carbon monoxide $(\mathrm{CO})$, sulfur dioxide $\left(\mathrm{SO}_{2}\right)$ and particulate matter less than $10 \mu \mathrm{m}$ in aerodynamic diameter $\left(\mathrm{PM}_{10}\right)$ were collected. The API follows the United States Environmental Protection Agency (USEPA) Pollution Standards Index for uniformity in air quality monitoring across countries [19].

Data on air pollutant levels were collected from 52 air-monitoring stations, which were distributed among all 16 states in Malaysia, from January 1, 2011 to December 31, 2013. Each monitoring station provided hourly concentration readings for all five pollutants. All air pollutant concentrations were standardized to $\mu \mathrm{g} / \mathrm{m}^{3}$. For each pollutant, a 3-year grand mean and the 3-year 95th percentile levels from the distribution of hourly values were computed for each state from each monitoring station. To estimate exposure of air pollution concentrations among TB cases, the air monitoring station nearest to the address of each TB patient was identified. 


\subsection{Statistical Analysis}

A descriptive statistical analysis was performed on socio-demographic characteristics of TB patients in Malaysia. Adjusted standardized incidence rates of TB in Malaysia were calculated for each state in Malaysia. Univariate analysis was done to obtain crude estimates for each factor associated with PTB. Standardized incidence rate was calculated to estimate the overall TB burden for each Malaysian state.

We used scatterplots to examine the relationships between the 3-year 95th percentiles of each air pollutants including API. Pearson correlation coefficient was used to assess those relationships that were significant at $\mathrm{p}$-value $<0.05$.

Multiple logistic regression models were performed to assess the associations between the dependent outcome variable of TB disease based on anatomy of infection ( 0 = EPTB, $1=$ PTB $)$ and air pollution-specific variables, controlling for important covariates. Preliminary analysis was performed to examine associations of PTB with each of the selected covariates. Separate analyses for each air pollutants were carried out to control for multicollinearity. Assessment for the main effects and confounding was taken into account in order to obtain estimates of the odds of PTB (compared to EPTB) with increases in air pollution. All significant covariates were included in the final model.

\section{Results}

\subsection{Sample Population}

There were 23,993 TB patients reported in the TBIS, Malaysia in 2013, of whom 66 (0.3\%) was diagnosed with MDR-TB and 1538 (6.4\%) were co-infected with HIV. All duplicates and 527 TB patients with unknown HIV status were excluded from this study. In total, 19,275 HIV negative TB patients and without MDR-TB were included in this study.

There were 16,903 (87.7\%) PTB and 2372 (12.3\%) EPTB cases. The proportion of TB cases was higher among males than females, those aged 33 to 49 years old, Malaysian citizens, Malay ethnics, those with at least secondary educations, and those with low income (Table 1). A high incidence of TB was reported in North Borneo, while all states in peninsular Malaysia except Kelantan state had incidence rates less than 60/100,000 populations. Distributions of incidence rates of TB by state and 3-year $95^{\text {th }}$ percentile of API are shown in Figure 1(a) (Peninsular Malaysia) and Figure 1(b) (Borneo Island).

Table 2 shows the unadjusted odds ratio for all host-related TB factors that associated with PTB. Having had TB before, crowding, smoking and diabetes increased the odds of PTB in relative to EPTB. BCG vaccination significantly decreased the odds of PTB.

\subsection{Air Pollution Exposure}

Figure 2 shows the weekly mean API from Jan 1, 2011, through December 31, 2013. The API showed a seasonal pattern, with higher levels between June and 


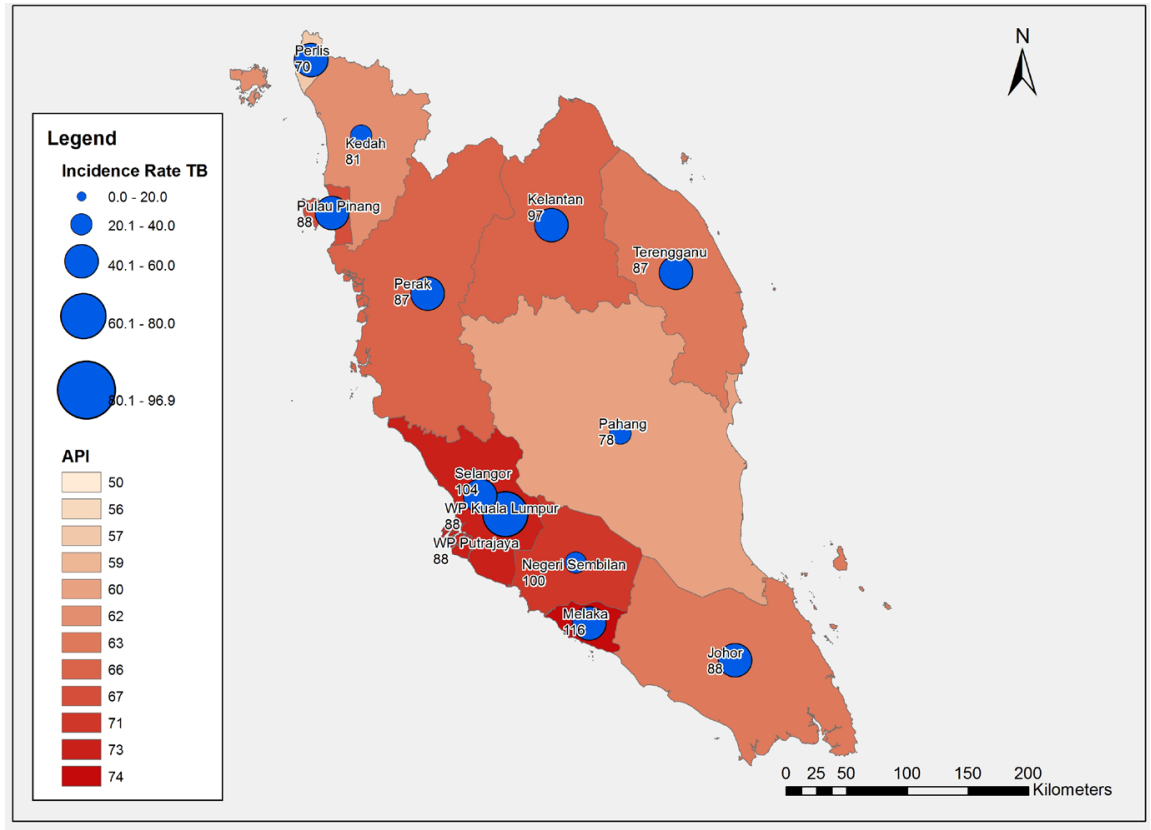

(a)

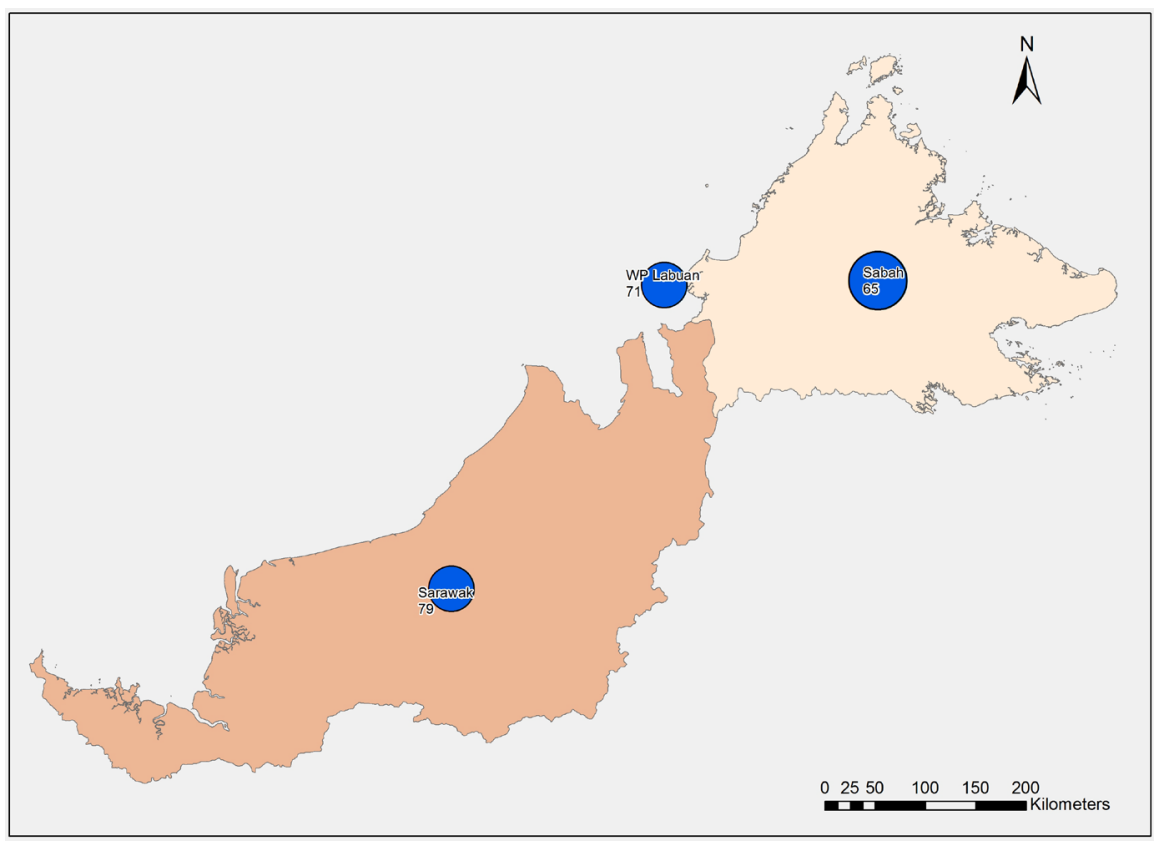

(b)

Figure 1. (a) Standardized incidence rates of TB and 3-year 95th percentile of Air Pollutant Index (API) for Peninsular Malaysia; (b) Standardized Incidence rates of TB and 3-year 95th percentile of Air Pollutant Index (API) for Borneo Island, Malaysia.

Table 1. Demographic characteristics of TB patients in Malaysia, 2013 ( $\mathrm{n}=19,275)$.

\begin{tabular}{cccc}
\hline Characteristics & All TB & Pulmonary TB & Extrapulmonary TB \\
\hline & $\mathbf{n}(\%)$ & $\mathbf{n}(\%)$ & $\mathbf{n}(\%)$ \\
\hline $\begin{array}{c}\text { Overall TB patients in Malaysia } \\
\text { Gender }\end{array}$ & 19,275 & $16,903(87.7)$ & $2372(12.3)$ \\
\hline
\end{tabular}




\section{Continued}

\begin{tabular}{|c|c|c|c|}
\hline Male & $12,189(63.2)$ & $11,007(65.1)$ & $1182(49.8)$ \\
\hline Female & $7086(36.8)$ & $5896(34.9)$ & $1190(50.2)$ \\
\hline \multicolumn{4}{|l|}{ Age (Years) } \\
\hline$<5$ & $245(1.3)$ & $195(1.2)$ & $50(2.1)$ \\
\hline 5 to 17 & $976(5.1)$ & $769(4.5)$ & $210(8.9)$ \\
\hline 18 to 29 & $4429(23.0)$ & $3787(22.4)$ & $642(27.1)$ \\
\hline 30 to 49 & $6343(33.0$ & $5577(33.0)$ & $766(32.3)$ \\
\hline 50 to 65 & 4599 (23.9) & $4094(24.2)$ & $505(21.3)$ \\
\hline$>65$ & $2680(13.9)$ & $2481(14.7)$ & $199(8.4)$ \\
\hline \multicolumn{4}{|l|}{ Nationality } \\
\hline Malaysian & $16,528(85.8)$ & $14,418(85.3)$ & $2111(89.0)$ \\
\hline Non-citizen & $2747(14.3)$ & $2486(14.7)$ & $261(11.0)$ \\
\hline \multicolumn{4}{|l|}{ Ethnicity } \\
\hline Malay & $8191(49.6)$ & $7063(49.0)$ & $1128(53.4)$ \\
\hline Chinese & $2823(17.1)$ & $2528(17.5)$ & $295(14.0)$ \\
\hline Indian & $1030(6.2)$ & $876(6.1)$ & $154(7.3)$ \\
\hline Borneo (Sarawakian) & $1549(9.4)$ & $1382(9.6)$ & $167(7.9)$ \\
\hline Borneo (Sabahan) & $2500(15.1)$ & $2174(15.1)$ & $326(15.4)$ \\
\hline Other & $434(2.6)$ & $392(2.7)$ & $42(2.0)$ \\
\hline \multicolumn{4}{|l|}{ Education Level } \\
\hline No formal education & $3724(19.3)$ & $3382(20.0)$ & $342(14.4)$ \\
\hline Primary education & $3875(20.1)$ & $3474(20.6)$ & $401(16.9)$ \\
\hline Secondary education & $9276(48.1)$ & $8088(47.8)$ & $1188(50.1)$ \\
\hline Tertiary education & $2214(11.5)$ & $1794(10.6)$ & $420(17.7)$ \\
\hline Other & $186(1.0)$ & $165(1.0)$ & $21(0.9)$ \\
\hline \multicolumn{4}{|l|}{ Income } \\
\hline Low $(<$ RM 3000) & $7198(85.8)$ & $6,260(86.3)$ & $938(82.5)$ \\
\hline Middle (RM 3000 - 7000) & $1140(13.6)$ & $952(13.1)$ & $188(16.5)$ \\
\hline High (>RM 7000) & $54(0.6)$ & $43(0.6)$ & $11(1.0)$ \\
\hline
\end{tabular}

Table 2. Univariate analysis of host-related TB factors for pulmonary TB relative to extra-pulmonary PTB.

\begin{tabular}{ccccc}
\hline Variable & Pulmonary TB & Extrapulmonary TB & cOR (95\% CI) & p-value \\
\hline BCG scar & $\mathbf{n}(\%)$ & $\mathbf{n}(\%)$ & & \\
Yes & $12,793(75.7)$ & $1934(81.5)$ & $0.705(0.632,0.787)$ & \\
No & $4111(24.3)$ & $438(18.5)$ & 1 & $<0.001$ \\
History of TB & & & & \\
Yes & $1112(6.6)$ & $96(4.0)$ & $1.669(1.349,2.066)$ & $<0.001$ \\
No & $15,792(93.4)$ & $2276(96.0)$ & 1 & \\
\hline
\end{tabular}




\section{Continued}

\begin{tabular}{ccccc}
\hline $\begin{array}{c}\text { Crowding } \\
\text { (number of people } \\
\text { per house) } \\
1 \text { to } 5\end{array}$ & $13,637(85.9)$ & $1983(87.9)$ & 1 & \\
6 to 10 & $2005(12.6)$ & $252(11.2)$ & $1.157(1.007,1.330)$ & 0.040 \\
$>10$ & $236(1.5)$ & $22(1.0)$ & $1.560(1.005,2.421)$ & 0.047 \\
Smoking Status & $5905(34.9)$ & $488(20.6)$ & $2.073(1.867,2.301)$ & $<0.001$ \\
Yes & $10,999(65.1)$ & $1884(79.4)$ & 1 & \\
No & & & $1.968(1.712,2.263)$ & $<0.001$ \\
Diabetes & $3043(18.0)$ & $238(10.0)$ & 1 & \\
Yes & $13,861(82.0)$ & $2134(90.0)$ & & \\
No & & & & \\
\hline
\end{tabular}

*Notes: BCG Scar indicates having been vaccinated with BCG. Smoking status defined as current smoking status and ever smoked in life.

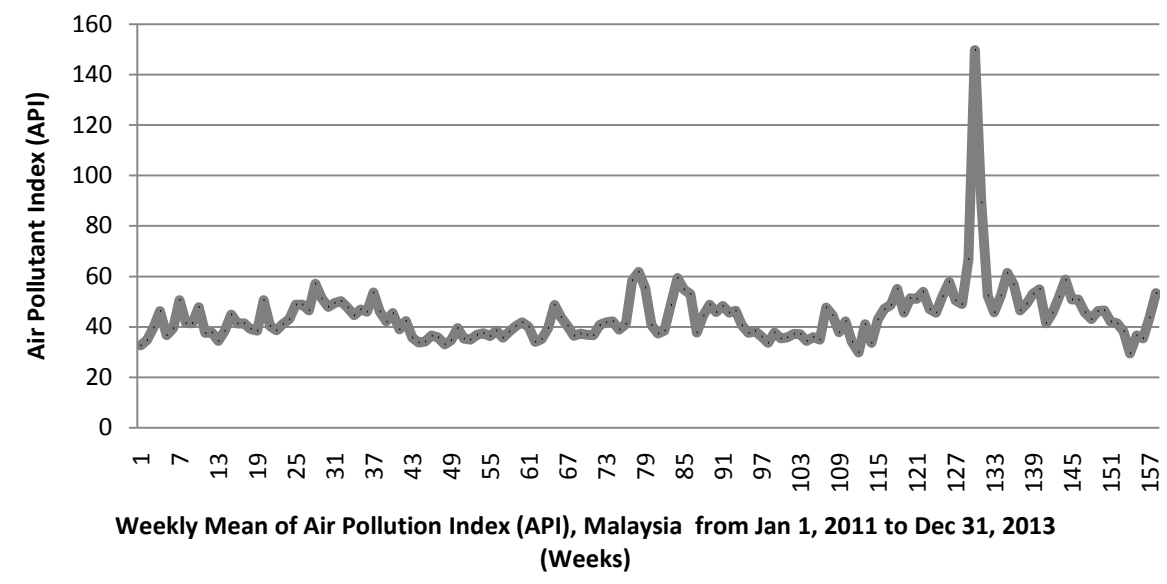

Figure 2. Weekly mean air pollutant index (API) from Jan 1, 2011-Dec 31, 2013. Notes: Air Pollution Index Standard: Moderate: 51 - 100; Unhealthy: 101 - 200.

August of each year. An exceptionally high peak in air pollution levels was observed in 2013, between June and August, exceeding the unhealthy level according to the Malaysian API standard.

Over the 3-year (2011-2013) period, the mean API in Malaysia was 45 (SD = $15.6)$ with a median of $40(\mathrm{IQR}=20)$. Of all air pollutants, $\mathrm{CO}$ showed the highest concentration, with a 3-year mean of $611.2 \mu \mathrm{g} / \mathrm{m}^{3}(\mathrm{SD}=459.18)$ and a maximum weekly concentration of $13,112.5 \mu \mathrm{g} / \mathrm{m}^{3}$. In contrast, $\mathrm{SO}_{2}$ showed the lowest concentrations with a mean of $4.8(\mathrm{SD}=7.4) \mu \mathrm{g} / \mathrm{m}^{3}$ and a maximum weekly concentration of $518.3 \mu \mathrm{g} / \mathrm{m}^{3}$ (Table 3). Among all states in Malaysia, Malacca showed the highest 3-year 95th percentile levels of API levels, while states in the north of Borneo Island showed low 3-year 95th percentile levels for API within 50 to 60 (Figure 1).

Pearson correlation analysis for the mean of 3 -year $95^{\text {th }}$ percentile of air pollution 
Table 3. Summary of the 3-year air pollution concentrations from January 1, 2011 through December 31, 2013.

\begin{tabular}{cccccc}
\hline Air Pollutant Exposure & Mean (SD) & Median (IQR) & $\mathbf{5 \%}$ & $\mathbf{9 5 \%}$ & Max \\
\hline Air Pollutant Index (API) & $45(15.6)$ & $40(20)$ & 22 & 65 & 663 \\
$\mathrm{PM}_{10}\left(\mu \mathrm{g} / \mathrm{m}^{3}\right)$ & $43(27.8)$ & $38(26)$ & 15 & 89 & 995 \\
$\mathrm{O}_{3}\left(\mu \mathrm{g} / \mathrm{m}^{3}\right)$ & $33.2(30.4)$ & $25.5(39.3)$ & 2.0 & 92.3 & 323.9 \\
$\mathrm{CO}\left(\mu \mathrm{g} / \mathrm{m}^{3}\right)$ & $611.2(459.2)$ & $492.4(435.2)$ & 160.3 & 1465.9 & $13,112.5$ \\
$\mathrm{SO}_{2}\left(\mu \mathrm{g} / \mathrm{m}^{3}\right)$ & $4.8(7.4)$ & $2.6(2.6)$ & 0 & 15.7 & 518.3 \\
$\mathrm{NO}_{2}\left(\mu \mathrm{g} / \mathrm{m}^{3}\right)$ & $17.77(16.1)$ & $13.17(18.8)$ & 1.9 & 50.8 & 238.9 \\
\hline
\end{tabular}

concentrations indicated that all pollutants had significant positive correlations with each other. $\mathrm{PM}_{10}$ and ozone levels had relatively strong correlations with the API, and $\mathrm{CO}$ and $\mathrm{NO}_{2}$ were strongly correlated with each other. The weakest correlation was observed between ozone and $\mathrm{SO}_{2}$ (Table A1).

Further logistic regression model analysis was done to assess the potential role of air pollutants and PTB. We ran separate models for API, and each air pollutants with PTB by controlling the following covariates: BCG vaccination, crowding, TB history, tobacco use, diabetes, nationality and ethnicity (Table A2). Among all the air pollutants, $\mathrm{PM}_{10}$ and $\mathrm{SO}_{2}$ were significantly associated with $\mathrm{PTB}$ relative to EPTB ( $\mathrm{p}<0.05$ ) (Figure 3). Relative to EPTB, the estimated odds of PTB increased by 1.006 (95\% CI: 1.002, 1.011) for each $1 \mu \mathrm{g} / \mathrm{m}^{3}$ increase in $\mathrm{PM}_{10}$. Similarly for exposure to sulfurdioxide, the estimated odds of PTB increased by 1.012 (95\%CI: 1.006, 1.019) for each $1 \mu \mathrm{g} / \mathrm{m}^{3}$ increase in $\mathrm{SO}_{2}$. API and other pollutants, such as $\mathrm{NO}_{2}, \mathrm{O}_{3}$ and $\mathrm{CO}$, showed no significant association with PTB relative to EPTB (Figure 3).

\section{Discussion}

To the best of our knowledge, this study was the first to explore the association of ambient air pollution and pulmonary TB in Malaysia. We postulated the potential role of ambient air pollutants that could specifically activate pulmonary TB disease relative to extrapulmonary TB. The exposure period for TB acquisition is imperative; hence, we chose a long exposure period to take into account a long latency period of TB disease development [17]. In doing so, we were specifically interested in examining air pollution effects by considering their toxicological and clinical properties that might aggravate the manifestation of pulmonary $\mathrm{TB}$ relative to extrapulmonary $\mathrm{TB}$.

Based on the Malaysian API classifications, the 3-year average API in Malaysia was at a good level while the 3-year 95th percentile API was moderate. Perhaps the finding that API was not a significant predictor of the odds of PTB reflected the fact that the API was relatively good. Most previous studies of air pollution and TB have not considered the API as a predictor variable, but rather focused on specific types of ambient air pollutants that potentially could impair health 


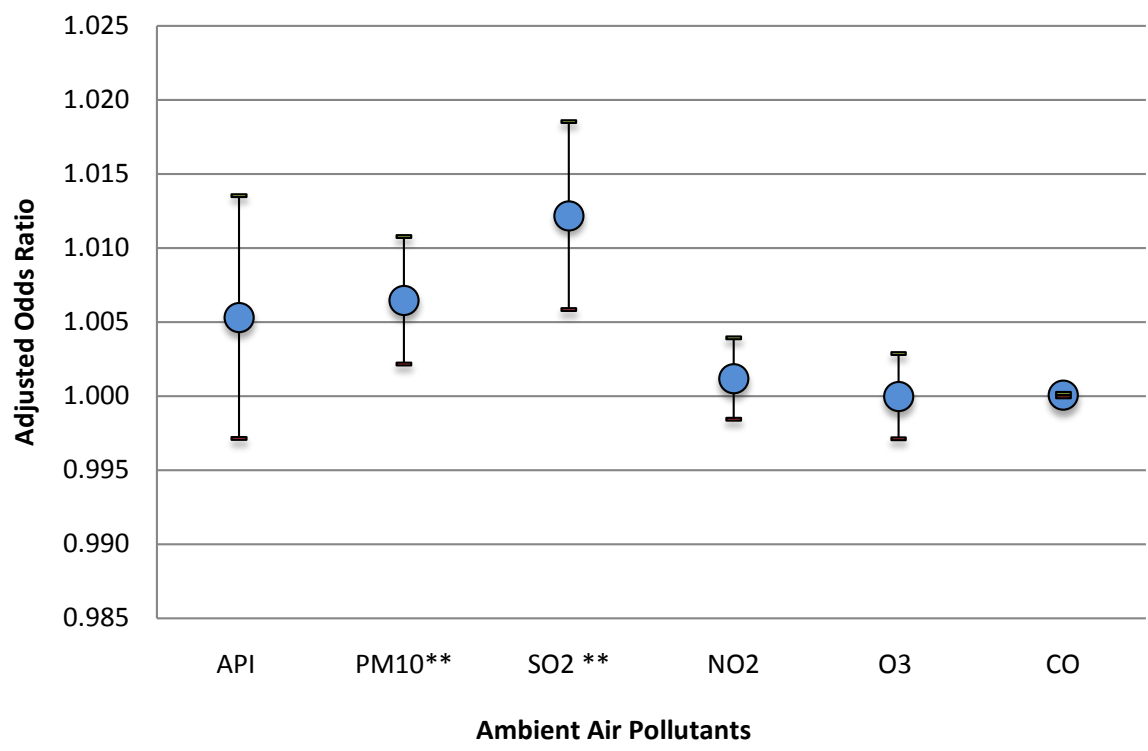

Figure 3. LR model estimated adjusted odds ratios (ORs) and $95 \%$ confidence intervals (CIs) for pulmonary TB relative to EPTB with increases in 3-year 95th percentile ambient air pollutant concentrations. Notes: ${ }^{* *}$ Statistically significant at $\mathrm{p}$-value $<0.05$ and $95 \%$ Confidence Interval does not include the null. Each parameter was adjusted for the following covariates including BCG vaccination, crowding, TB history, tobacco use, diabetes, nationality and ethnicity.

[20] [21]. To support our findings, one study reported long-term exposure of air pollutants measured with API did not show significant predictor to emergency admissions [22]. Despite the study measured different health outcomes, we believed the use of a single weighted parameter by combining various air pollutants incapacitates to predict the chronic health effects that associated with ambient air exposure. However, in this study we found single pollutants such as $\mathrm{PM}_{10}$ and $\mathrm{SO}_{2}$ have significantly associated with PTB as compared to other ambient air pollutants.

There are disputes pertaining to the role of $\mathrm{PM}_{10}$ and TB. Many studies reported significant contributions of $\mathrm{PM}_{10}$ to incremental daily mortality and excess risk of cardiovascular and respiratory diseases [11] [23] [24] [25] but not so much on infectious diseases. $\mathrm{PM}_{10}$ characterized by coarse particles which deposit in the upper respiratory tract, and with prolong exposure can reduce lung function by $3 \%$ to $6 \%$ [13] [23]. Controlling for other covariates, our study found significant association between $\mathrm{PM}_{10}$ and PTB. There were studies that could have supported our findings where incremental exposure of $\mathrm{PM}_{10}$ increased the odds of TB [26]. While another study reported significant association between outbreak of TB during dust storm episodes in China [27]. Inhalation of $\mathrm{PM}_{10}$ could increase the risk of infection and impair defense mechanisms in the airways and lungs [28]. This pathophysiological impact of $\mathrm{PM}_{10}$ causes alteration of macrophages and alveolar inflammation and thus permits bacterial proliferation [29] [30]. Interestingly, this is further explains that higher exposure of $\mathrm{PM}_{10}$ caused longer duration for sputum conversion among TB-positive cul- 
tures [26].

In contrast, another ecological study utilizing 14 years of data showed no association between $\mathrm{PM}_{10}$ and $\mathrm{TB}$ but specifically for $\mathrm{PM}_{2.5}$ which have shown significant associations with TB [21]. However factor such as PM concentrations in the study declined steadily throughout their study period, and the absence of variability in air pollution concentrations might have influenced the findings [21]. Stratified by sex, other study in South Korea found $\mathrm{PM}_{10}$ was not a significant predictor to TB despite the $\mathrm{PM}_{10}$ concentrations exceeded the national air standards [20].

In this study, among of all the ambient air pollutants, $\mathrm{SO}_{2}$ contributed to the lowest concentrations and prolong exposure was significantly associated with PTB. Our findings were consistent with other study in South Korea showing the role of $\mathrm{SO}_{2}$ in $\mathrm{TB}$ infection despite we did not stratified the $\mathrm{SO}_{2}$ exposure by sex [20]. However, the study in South Korea found only men were susceptible to TB in relation to $\mathrm{SO}_{2}$ exposure [20]. This occurrence could perhaps due to the men lifestyles including occupational factors, which involve $\mathrm{SO}_{2}$ exposure and time spent outdoor [9]. Data from severe air pollution episodes in London had indicated that $\mathrm{SO}_{2}$ and particulates synergistically increased acute morbidity and mortality, implying that particles were more toxic in the presence of $\mathrm{SO}_{2}$ [9] [30]. Our study also indicates significant correlation between $\mathrm{SO}_{2}$ and $\mathrm{PM}_{10}$ despite $\mathrm{SO}_{2}$ did not have strong correlation with $\mathrm{PM}_{10}$ compared to other air pollutants. $\mathrm{SO}_{2}$ is a highly soluble gas and a known respiratory tract irritant that can penetrate to distal airways and decrease lung function [9]. It impairs mucociliary clearance and causes inflammation that substantially increases the risk of infections [9] [31].

Controlling for other covariates, we did not find associations of $\mathrm{NO}_{2}$, ozone and $\mathrm{CO}$ with PTB. This was consistent with most other studies [20] [32]. However, a nested case-control study in setting with low air pollution levels and low TB rates found that exposure to high levels of $\mathrm{NO}_{2}$ and $\mathrm{CO}$ was positively associated with PTB [33]. $\mathrm{NO}_{2}$ and ozone are ubiquitous oxidant pollutants in the environment, and they could debilitate lung functions at the cellular level [9]. However, our study seems to disagree that those pollutants did not facilitate the developmental of PTB. This finding was consistent with several studies investigating the role of reactive nitrogen species as antimicrobials, including the presence of nitrogen and oxygen species that could inhibit the proliferation of intracellular mycobacteria [31] [34]. Among healthy individuals, $\mathrm{NO}_{2}$ at lower concentrations increases airway activity without affecting lung function [9]. Currently, there are limited epidemiological studies or clinical evidence on the effects of $\mathrm{NO}_{2}$ in human host defense [9]. However, $\mathrm{NO}_{2}$ is recognized as an effect modifier, particularly for vulnerable people with low immunity [9] [35].

Ozone causes acute decline of lung function in healthy individuals [25]. Information about possible associations of ozone and susceptibility to respiratory infections is still nebulous [9]. However, findings from in vitro and animal stu- 
dies suggested that ozone could alter macrophage function and decrease phagocytosis [9] [32]. Ozone also interacts synergistically with $\mathrm{SO}_{2}$ to cause severe lung dysfunction [9]. However, we found that ozone and $\mathrm{SO}_{2}$ had the weakest correlation of the air pollutants studied. Unlike other ambient air pollutants, exposure to high levels of $\mathrm{CO}$ is mostly associated with acute poisoning [9]. Most clinical studies have shown an association between $\mathrm{CO}$ and cardiovascular disease, but findings regarding $\mathrm{CO}$ and bacterial infection are very limited [9].

The API in Borneo Island was good and lower than that in Peninsular Malaysia. Hence, TB incidence was distinctively higher in Borneo Island than that the peninsular Malaysia. This implies the API is not a valid indicator to monitor TB infection that further supports our findings as discussed earlier. Numerous TB factors associated with PTB infection that includes people from the Sabahan and Sarawakian who mostly live in the Borneo Island. Differences in TB susceptibility may be associated with factors such as co-morbidities, crowding, poverty, housing structure, and lifestyle; for example, heavy alcohol and tobacco consumption might aggravate TB infection among some ethnic populations [14].

\section{Limitations}

This study had several limitations. First, it was a retrospective data analysis using surveillance data of a TB cohort in 2013 where we were restricted to a TB case-only analysis. Second, we estimated ambient air pollution exposures based on data obtained from the air monitoring station nearest to the patients' home addresses. We did not collect data from personal air monitoring or ask patients about time spent outdoors to more accurately estimate patients' exposure level. Third, we did not control for indoor air exposure. We used smoking as a proxy in this regard and did not interview patients about their direct or passive exposure to tobacco smoke. Fourth, we did not include meteorology data such as rainfall, daily temperature and humidity despite all these factors could influence the concentration of air pollutants [11]. However, investigators have reported, that environmental factors such as season temperature, rainfall, wind speed, wind direction and humidity did not influence the abundance of bacteria in the environment, though they did not examine specific ambient bacteria such as $M$. tuberculosis [36].

\section{Conclusions}

This was a preliminary study utilizing TB cases that distinguished clinical manifestations between PTB and EPTB. We would like to propose future study using ecological case-control study design by including healthy individuals as the non-TB cases among the Malaysian population. We also propose future studies to include lags, selection of exposure period to precisely estimate the impact of ambient air pollution exposure on TB. We further suggest future study to include $\mathrm{PM}_{2.5}$, which is more potent to respiratory health by a magnitude of 15 to $30 \%$ greater than $\mathrm{PM}_{10}$. Additionally, more studies have reported that $\mathrm{PM}_{2.5}$ 
could significantly hamper the pathophysiologic responses that impact many health outcomes [23] [24] [29].

This study provides evidences on the associations between ambient air pollutants such as $\mathrm{PM}_{10}$ and $\mathrm{SO}_{2}$ with PTB. API in Malaysia was at the moderate level during the study period and had no impact with the exacerbation of PTB. Thus, API was not predictive in this regard. Similar studies in areas with markedly poorer APIs might be worth pursuing.

\section{Acknowledgements}

We would like to thank Dr. Jeremy Sarnat and Dr. Neel Gandhi from Emory University, Rollins School of Public Health, Atlanta, GA for their technical inputs and feedbacks for this write-up. We thank the Director of Disease Control and Director of Institute for Public Health Malaysia for their support to conduct this study. Finally, the authors are grateful to the Director General of Health, Malaysia for allowing us to publish the findings of this study. This research did not receive any specific grant from funding agencies in the public, commercial, or not-for-profit sectors. This study obtained the ethical approval from the Medical Research and Ethics Committee, Ministry of Health Malaysia (NMRR: 17-331-33824).

\section{Author Contributions}

Conceptualization: MHAM and TGH; Methodology: SES and MSMN; Software: MHAM and MHH; Formal analysis: MHAM and MHH; Data curation: AR, SYP, MHH, and MHAM; Investigation: MHAM, AR, NAL and SYP; Writing-original preparation: MHAM, MHH; Writing-review and editing: NAL, SES, MSMN, AR; Supervision: TGH, SES.

\section{Conflicts of Interest}

The authors declare no conflict of interest.

\section{References}

[1] Organization, W.H. (2017) Global Tuberculosis Report 2017; WHO/HTM/TB/2017.23. World Health Organization, Geneva, 249.

[2] IHME (2017) I.f.H.M.a.E. GBD Compare Data Visualization. Washington, U.o., Ed. IHME, Seattle.

[3] Pai, M., Behr, M.A., Dowdy, D., Dheda, K., Divangahi, M., Boehme, C.C., Ginsberg, A., Swaminathan, S., Spigelman, M., Getahun, H., et al. (2016) Tuberculosis. Nature Reviews Disease Primers, 2, 16076. https://doi.org/10.1038/nrdp.2016.76

[4] Organization, W.H. (2017) Tuberculosis Fact Sheet. http://www.who.int/mediacentre/factsheets/fs104/en/

[5] Nana Yakam, A., Noeske, J., Dambach, P., Bowong, S., Fono, L.A. and Ngatchou-Wandji, J. (2014) Spatial Analysis of Tuberculosis in Douala, Cameroon: Clustering and Links with Socio-Economic Status. The International Journal of Tuberculosis and Lung Disease. The Official Journal of the International Union against 
Tuberculosis and Lung Disease, 18, 292-297. https://doi.org/10.5588/ijtld.13.0573

[6] Liew, S.M., Khoo, E.M., Ho, B.K., Lee, Y.K., Mimi, O., Fazlina, M.Y., Asmah, R., Lee, W.K., Harmy, M.Y., Chinna, K., et al. (2015) Tuberculosis in Malaysia: Predictors of Treatment Outcomes in a National Registry. The International Journal of Tuberculosis and Lung Disease: The Official Journal of the International Union against Tuberculosis and Lung Disease, 19, 764-771.

https://doi.org/10.5588/ijtld.14.0767

[7] The Lancet Diabetes (2014) Diabetes and Tuberculosis-A Wake-Up Call. The lancet. Diabetes \& Endocrinology, 2, 677. https://doi.org/10.1016/S2213-8587(14)70192-5

[8] Sumpter, C. and Chandramohan, D. (2013) Systematic Review and Meta-Analysis of the associations between Indoor Air Pollution and Tuberculosis. Tropical Medicine \& International Health: TM \& IH, 18, 101-108.

https://doi.org/10.1111/tmi.12013

[9] Society, A.T. (1996) Health Effects of Outdoor Air Pollution. Committee of the Environmental and Occupational Health Assembly of the American Thoracic Society. American Journal of Respiratory and Critical Care Medicine, 153, 3-50. https://doi.org/10.1164/ajrccm.153.1.8542133

[10] Glickman, M.S. and Jacobs Jr., W.R. (2001) Microbial Pathogenesis of Mycobacterium Tuberculosis: Dawn of a Discipline. Cell, 104, 477-485. https://doi.org/10.1016/S0092-8674(01)00236-7

[11] Wong, C.-M., Vichit-Vadakan, N., Kan, H. and Qian, Z. (2008) Public Health and Air Pollution in Asia (PAPA): A Multicity Study of Short-Term Effects of Air Pollution on Mortality. Environmental Health Perspectives, 116, 1195-1202. https://doi.org/10.1289/ehp.11257

[12] Organization, W.H. (2016) Ambient (Outdoor) Air Quality and Health. World Health Organization, Geneva.

[13] Kampa, M. and Castanas, E. (2008) Human Health Effects of Air Pollution. Environmental Pollution, 151, 362-367. https://doi.org/10.1016/j.envpol.2007.06.012

[14] Shajahan, R., Navaratnam, P., Kasinathan, G., Kadirvelu, A. and Pillai, N. (2016) Predictors of Re-Emerging Tuberculosis: A Review. Open Access Library Journal, 3, 1. https://doi.org/10.4236/oalib.1102520

[15] Nantha, S. (2014) A Review of Tuberculosis Research in Malaysia. Medical Journal of Malaysia, 69, 88.

[16] Afroz, R., Hassan, M.N. and Ibrahim, N.A. (2003) Review of Air Pollution and Health Impacts in Malaysia. Environmental Research, 92, 71-77. https://doi.org/10.1016/S0013-9351(02)00059-2

[17] Heymann, D.L. (2014) Control of Communicable Diseases Manual. 20th Edition, APHA Press, Washington DC, 729.

[18] Malaysia, M.o.H. (2012) Management of Tuberculosis. In: Abdul Rahman, J.A., Ed., Malaysia Health Technology Assessment Section, 3rd Edition, 109.

[19] DOE (2000) A Guide to Air Pollutant Index (API) in Malaysia. 4th Edition, Department of Environment, Ministry of Science, Technology and Environment, Kuala Lumpur.

[20] Hwang, S.S., Kang, S., Lee, J.Y., Lee, J.S., Kim, H.J., Han, S.K. and Yim, J.J. (2014) Impact of Outdoor Air Pollution on the Incidence of Tuberculosis in the Seoul Metropolitan Area, South Korea. Korean Journal of Internal Medicine, 29, 183-190. https://doi.org/10.3904/kjim.2014.29.2.183 
[21] Smith, G., Schoenbach, V.J., Richardson, D.B. and Gammon, M.D. (2014) Particulate Air Pollution and Susceptibility to the Development of Pulmonary Tuberculosis Disease in North Carolina: An Ecological Study. International Journal of Environmental Health Research, 24, 103-112. https://doi.org/10.1080/09603123.2013.800959

[22] Tseng, C.H., Lu, L.C., Lan, S.H., Hsieh, Y.P. and Lan, S.J. (2017) Relationship between Emergency Care Utilization, Ambient Temperature, and the Pollution Standard Index in Taiwan. International Journal of Environmental Health Research, 27, 344-354. https://doi.org/10.1080/09603123.2017.1339782

[23] Kim, K.-H., Kabir, E. and Kabir, S. (2015) A Review on the Human Health Impact of Airborne Particulate Matter. Environment International, 74, 136-143. https://doi.org/10.1016/j.envint.2014.10.005

[24] Lu, F., Xu, D., Cheng, Y., Dong, S., Guo, C., Jiang, X. and Zheng, X. (2015) Systematic Review and Meta-Analysis of the Adverse Health Effects of Ambient PM2.5 and PM10 Pollution in the Chinese Population. Environmental Research, 136, 196-204. https://doi.org/10.1016/j.envres.2014.06.029

[25] WHO Regional Office for Europe (2013) In Review of Evidence on Health Aspects of Air Pollution-REVIHAAP Project. Technical Report, WHO Regional Office for Europe (c) World Health Organization, Copenhagen.

[26] Chen, K.-Y., Chuang, K.-J., Liu, H.-C., Lee, K.-Y., Feng, P.-H., Su, C.-L., Lin, C.-L., Lee, C.-N. and Chuang, H.-C. (2016) Particulate Matter Is Associated with Sputum Culture Conversion in Patients with Culture-Positive Tuberculosis. Therapeutics and Clinical Risk Management, 12, 41-46.

[27] Wang, Y., Wang, R., Ming, J., Liu, G., Chen, T., Liu, X., Liu, H., Zhen, Y. and Cheng, G. (2016) Effects of Dust Storm Events on Weekly Clinic Visits Related to Pulmonary Tuberculosis Disease in Minqin, China. Atmospheric Environment, 127, 205-212. https://doi.org/10.1016/j.atmosenv.2015.12.041

[28] Tighe, R.M., Wheeler, J. and Hollingsworth, J.W. (2015) Air Pollution and Immune Function. In: Nadadur, S.S. and Hollingsworth, J.W., Eds., Air Pollution and Health Effects, Springer, London, 289-321. https://doi.org/10.1007/978-1-4471-6669-6_11

[29] Hao, Y., Zhang, G., Han, B., Xu, X., Feng, N., Li, Y., Wang, W., Kan, H., Bai, Z., Zhu, Y., et al. (2017) Prospective Evaluation of Respiratory Health Benefits from Reduced Exposure to Airborne Particulate Matter. International Journal of Environmental Health Research, 27, 126-135. https://doi.org/10.1080/09603123.2017.1292497

[30] Chauhan, A.J. and Johnston, S.L. (2003) Air Pollution and Infection in Respiratory Illness. British Medical Bulletin, 68, 95-112. https://doi.org/10.1093/bmb/ldg022

[31] Chen, T.-M., Kuschner, W.G., Gokhale, J. and Shofer, S. (2007) Outdoor Air Pollution: Nitrogen Dioxide, Sulfur Dioxide, and Carbon Monoxide Health Effects. The American Journal of the Medical Sciences, 333, 249-256. https://doi.org/10.1097/MAJ.0b013e31803b900f

[32] Jassal, M.S., Bakman, I. and Jones, B. (2018) Correlation of Ambient Pollution Levels and Heavily-Trafficked Roadway Proximity on the Prevalence of Smear-Positive Tuberculosis. Public Health, 127, 268-274. https://doi.org/10.1016/j.puhe.2012.12.030

[33] Smith, G.S., Van Den Eeden, S.K., Garcia, C., Shan, J., Baxter, R., Herring, A.H., Richardson, D.B., Van Rie, A., Emch, M. and Gammon, M.D. (2016) Air Pollution and Pulmonary Tuberculosis: A Nested Case-Control Study among Members of a Northern California Health Plan. Environmental Health Perspectives, 124, 761-768. 
https://doi.org/10.1289/ehp.1408166

[34] Fang, F.C. (2004) Antimicrobial Reactive Oxygen and Nitrogen Species: Concepts and Controversies. Nature Reviews Microbiology, 2, 820-832. https://doi.org/10.1038/nrmicro1004

[35] Steenland, K. and Savitz, D.A. (1997) Topics in Environmental Epidemiology. Oxford University Press, Oxford.

[36] Park, J., Ichijo, T., Nasu, M. and Yamaguchi, N. (2016) Investigation of Bacterial Effects of Asian Dust Events through Comparison with Seasonal Variability in Outdoor Airborne Bacterial Community. Scientific Reports, 6, Article No. 35706. https://doi.org/10.1038/srep35706

\section{Supplementary Materials}

Table A1. Pearson correlation coefficients of the 3-year 95th-percentile air pollutant concentrations.

\begin{tabular}{ccccccc}
\hline & API & PM10 & $\mathrm{SO}_{2}$ & $\mathrm{NO}_{2}$ & $\mathrm{O}_{3}$ & $\mathrm{CO}$ \\
\hline $\mathrm{API}$ & 1.00 & & & & & \\
$\mathrm{PM} 10$ & 0.87 & 1.00 & & & & \\
$\mathrm{SO}_{2}$ & 0.42 & 0.40 & 1.00 & & & \\
$\mathrm{NO}_{2}$ & 0.69 & 0.52 & 0.62 & 1.00 & & \\
$\mathrm{O}_{3}$ & 0.86 & 0.55 & 0.40 & 0.63 & 1.00 & \\
$\mathrm{CO}$ & 0.69 & 0.64 & 0.59 & 0.93 & 0.52 & 1.00 \\
\hline
\end{tabular}

Note: All correlation coefficients were statistically significant at p-value $<0.05$.

Table A2. LR model estimated crude and adjusted odds ratios (ORs) and 95\% confidence intervals (CIs) for pulmonary TB and the 3-year 95th percentile of ambient air pollutant concentrations.

\begin{tabular}{ccc} 
Model & \multicolumn{2}{c}{ 95 Percentile } \\
3-year exposure \\
\hline PTB = 1, EPTB = 0) & Crude OR $(95 \% \mathrm{CI})$ & Adjusted OR* $(95 \% \mathrm{CI})$ \\
\hline Model 1: API & $0.993(0.988,0.998)^{\star *}$ & $1.005(0.997,1.014)$ \\
Model 2: PM10 & $0.999(0.997,1.003)$ & $1.006(1.002,1.011)^{\star *}$ \\
Model 3: $\mathrm{SO}_{2}$ & $1.004(0.999,1.009)$ & $1.012(1.006,1.019)^{\star *}$ \\
Model 4: $\mathrm{NO}_{2}$ & $0.999(0.996,1.001)$ & $1.001(0.998,1.004)$ \\
Model 5: $\mathrm{O}_{3}$ & $0.996(0.995,0.998)^{\star *}$ & $0.999(0.997,1.003)$ \\
Model 6: $\mathrm{CO}^{*}$ & $0.999(0.999,1.000)$ & $1.000(0.999,1.000)$ \\
\hline
\end{tabular}

Notes: ${ }^{*}$ Statistically Significant at p-value $<0.05$ and $95 \%$ Confidence Interval does not include the null. Each parameter was adjusted for the following covariates including BCG vaccination, crowding, TB history, tobacco use, diabetes, nationality and ethnicity. 